\title{
Micro- and macro-viscosity relations in high concentration antibody solutions
}

DOI:

10.1016/j.ejpb.2020.06.007

\section{Document Version}

Accepted author manuscript

Link to publication record in Manchester Research Explorer

\section{Citation for published version (APA):}

Shah, M., Corbett, D., Lanzaro, A., Roche, A., Sibanda, N., Davis, P., Uddin, S., van der Walle, C. F., Curtis, R., \& Pluen, A. (2020). Micro- and macro-viscosity relations in high concentration antibody solutions. European Journal of Pharmaceutics and Biopharmaceutics, 153, 211-221. [10.1016/j.ejpb.2020.06.007].

https://doi.org/10.1016/j.ejpb.2020.06.007

Published in:

European Journal of Pharmaceutics and Biopharmaceutics

\section{Citing this paper}

Please note that where the full-text provided on Manchester Research Explorer is the Author Accepted Manuscript or Proof version this may differ from the final Published version. If citing, it is advised that you check and use the publisher's definitive version.

\section{General rights}

Copyright and moral rights for the publications made accessible in the Research Explorer are retained by the authors and/or other copyright owners and it is a condition of accessing publications that users recognise and abide by the legal requirements associated with these rights.

\section{Takedown policy}

If you believe that this document breaches copyright please refer to the University of Manchester's Takedown Procedures [http://man.ac.uk/04Y6Bo] or contact uml.scholarlycommunications@manchester.ac.uk providing relevant details, so we can investigate your claim.

\section{OPEN ACCESS}


Micro- and macro-viscosity relations in high concentration antibody solutions

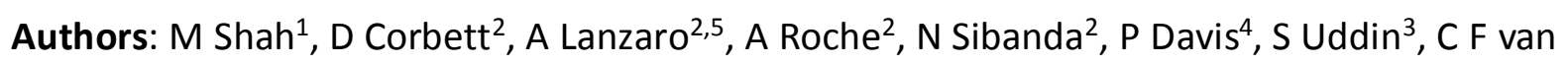
der Walle ${ }^{3}$, R Curtis ${ }^{2}$ and A Pluen ${ }^{1^{*}}$

\section{Affiliations:}

${ }^{1}$ Division of Pharmacy and Optometry, School of Health Sciences, Faculty of Biology, Medicine and Health, University of Manchester, Manchester, M13 9PT, UK

${ }^{2}$ School of Chemical Engineering and Analytical Sciences, Faculty of Engineering and Physical Sciences, University of Manchester, Manchester, M13 9PL, UK

${ }^{3}$ Dosage Form Design and Development, AstraZeneca, Sir Aaron Klug Building, Granta Park, Cambridge CB21 6GH, UK

4 Present address: Department of Molecular Biology and Biotechnology, University of Sheffield, Sheffield S10 2TN

${ }^{5}$ Present address: Institute of Systems Rheology, Guangzhou University, Guangzhou, China

\section{Corresponding author:}

*Alain Pluen, division of Pharmacy and Optometry, School of Health Sciences, University of Manchester, M13 9PT, UK

Email: alain.pluen@manchester.ac.uk, Tel: (0)161-275-1792 


\begin{abstract}
Molecular crowding in highly concentrated monoclonal antibody (mAb) solutions results in significant increases in viscosity, which complicates fill-finish steps and patient administration by subcutaneous injection. As viscosity measurements for optimization of the mAb formulation require significant amounts of material not always available in early development, fluorescence correlation spectroscopy (FCS) is evaluated as a potential ultralow volume technique for viscosity measurement of high concentration protein solutions assuming the Generalised Stokes Einstein relation (GSE) remains valid. Using like-charge fluorescent tracers of different sizes, FCS provided measurements of microviscosities which were compared to the macroviscosity. After parametrising the protein concentration dependence of the viscosity by the exponential coefficient $(k)$ of a simple exponential model, FCS derived $k$-values of like-size tracer to the crowder followed the same ordering as the macroviscosity derived $k$-values with respect to solvent conditions. Furthermore, $k$ and the diffusion-derived protein-protein interaction parameter, $k_{D}$, are linked, and, attractive conditions for mAbs result in a stronger concentration dependence of the viscosity. For tracers and crowders of like-size, a key result is negative deviations from the GSE relation are observed in presence of strong attractive interactions between crowder molecules. These data demonstrate that FCS has application to the screening of high concentration mAb solutions for formulation selection.
\end{abstract}

Keywords: fluorescence correlation spectroscopy, viscosity, protein solutions, antibodies, molecular crowding, Generalised Stokes Einstein relation 


\section{Introduction}

The viscosity of high concentration protein solutions (> $100 \mathrm{~g} / \mathrm{L}$ ) is governed by weak protein-protein interactions and transient conformational changes $[1,2]$ which are dependent on environmental parameters such as the solution dielectric constant, ionic strength and $\mathrm{pH}[3,4]$. Apart from traditional rheological techniques, microviscosities can be characterized from measurements of the long-time self-diffusion or the mean square displacement of tracers and applying the generalised Stokes Einstein (GSE) relation [5]. This was first demonstrated by Muramatsu and Minton, who studied the diffusion of various fluorescently labelled tracer proteins in solutions crowded with globular proteins via measurements of boundary spreading [6], showing that the fractional reduction of the diffusion of the tracer increased with increasing size of tracer species and with decreasing size of crowding protein. Additional techniques commonly used for measuring tracer diffusion include pulsed-field-gradient $\operatorname{NMR}[5,7,8]$ or dynamic light scattering (DLS) with micron sized tracer particles[9].

FCS is an ideal tool to study the long-time translational self-diffusion of tracer particles in monoclonal antibody $(\mathrm{mAb})$ solutions because fluorescence fluctuations are measured in a microscope focal volume of less than one femtolitre, which, in turn, requires very small protein sample volumes [8, 10-12]. The long-time self-diffusion coefficient derived from FCS measurements relates to a solution microviscosity, $\eta^{\prime}$, according to the generalized StokesEinstein (GSE) relation [5].

$D=\frac{k_{B} T}{6 \pi \eta^{\prime} R_{H}}$

where $k_{B} T$ denotes the thermal energy, $R_{H}$ is the hydrodynamic radius of the fluorescently labelled tracer. Being able to use the GSE requires knowing how to relate the microviscosity $\eta^{\prime}$ to the macroviscosity $\eta$ [13], [14] [15]. It is common to define a retardation factor, $r^{\prime}$ in terms of the relative diffusion coefficient $D_{0} / D\left(\right.$ or $\left.\eta^{\prime} / \eta_{0}\right)$, and a macroscopic retardation factor $r$, which is equal to the relative viscosity $\eta / \eta_{0}$. The GSE is applicable when the retardation factors are equal to each other, while negative deviations correspond to when the GSE underpredicts the macroscopic viscosity $\left(r^{\prime}<r\right)$, and positive deviations occur when GSE overpredicts the slowing down of motion or when $r^{\prime}>r$. 
When the GSE is applicable $\left(r^{\prime}=r\right)$, the microviscosity is equal to the macroviscosity: this case is observed when using tracer particles with sizes much larger than the crowder protein, [16] but a key question is the applicability of the GSE when the tracer particle size is similar to that of the crowder. This issue has been addressed by different groups using fluorescence correlation spectroscopy (FCS) to measure the diffusion of a range of tracers in polymeric crowders [17-19]. Holyst et al. measured the self-diffusion of rhodamine 6G, lysozyme, apoferritin and silica spheres in concentrated polyethylene glycol (PEG) solutions (molecular weights 6000, 12000, $20000 \mathrm{~g} / \mathrm{mol}$ at concentrations $0-50 \% \mathrm{v} / \mathrm{v}$ ). They found the motion of nanoscopic probes in PEG solutions could be related to the macroviscosity of aqueous PEG solutions [17] using a semi-empirical model; following analyses they suggested that a probe needed to have four times the hydrodynamic radius of PEG to feel the macroviscosity [18]. Lavalette et al. [19] measured the rotational and translational selfdiffusion of proteins (GFP, BSA, $\alpha 2$-macroglobulin, earthworm haemoglobin and integral earthworm haemoglobin) in various dextran crowders (from 6kDa to 2,000kDa). They described the variation of the diffusion ratio as a function of the relative macroviscosity by including an exponent (q) related to the ratio of tracer size over the crowder size. In an apparent conflict with Muramatsu and Minton [6], they suggested translation and rotation of proteins were accelerated in dilute macromolecular crowders compared to their value in solvents of the same viscosity. In other studies, when using colloidal crowding agents, the GSE is applicable for describing long-time self-diffusion coefficients when the tracer and crowder particles have the same size [20, 21]. However, it still remains unclear how size difference between the crowder and tracer impacts protein solutions. Muramatsu and Minton [6] measured the diffusion coefficients for four types of tracer proteins with sizes ranging between 17 and $150 \mathrm{kDa}$ each in solutions with four different crowder proteins with sizes between $13 \mathrm{kDa}$ and $150 \mathrm{kDa}$. Analagous to polymers crowders, the retardation of a tracer protein decreased with increasing size of the crowder protein. However, Wang et al. [16] found that polymers do not mimic the behaviour of protein crowders when using chymotrypsin inhibitor $2(\mathrm{Cl} 2)$ as a tracer protein. Negative deviations to the GSE occur when using synthetic polymers as crowders, which is expected because the polymer molecular weights are ten times as large as $\mathrm{Cl}$. However, in concentrated solutions of lysozyme, $\mathrm{Cl} 2$ motion is retarded more than expected from the macroscopic viscosity, while 
the GSE is applicable in crowded solutions with bovine serum albumin (BSA) or ovalbumin, even though BSA and ovalbumin are larger in size than $\mathrm{Cl} 2$.

Another key factor is direct tracer interactions with the crowder molecules that impede or retard the tracer motion. The qualitative difference in diffusivity of $\mathrm{Cl} 2$ was attributed to specific interactions of $\mathrm{Cl} 2$ with protein crowders that do not exist with inert polymers, which was also evident from measurements of rotational diffusion coefficients that are more sensitive to tracer-crowder association. Positive deviations in the GSE have also been observed in mixtures of labelled apomyoglobin with either human serum albumin (HSA) or ribonulease-A (RNase-A) [22]. The observed behaviour followed predictions based on Muramatsu and Minton's model [6]. Attractive electrostatic interactions between the crowder proteins (HSA or RNAse) and the tracer (apomyoglobulin) could not be ruled out as a cause of the GSE positive deviations [22]. A similar conclusion was reached in a study using mixtures of the Src-homology 3 (SH3) domain with BSA [5]. SH3 was chosen as a model protein because the protein binds to arginine and proline rich motifs that exist on the surface of BSA. The binding between SH3 and BSA was confirmed by isothermal titration calorimetry, which provided direct evidence that strong tracer-crowder associations cause significant tracer retardation. In contrast, when tracer and crowder are the same protein, the GSE is applicable for describing self-diffusion coefficients. In addition to solutions containing SH3 or BSA, the agreement has been observed for $\alpha \mathrm{B}$-crystallin and lysozyme when using a labelled tracer of the same crowder protein [8]. Out of these proteins, hard sphere models capture the thermodynamic and transport properties only for $\alpha \mathrm{B}$-crystallin. For BSA and lysozyme, fitting to structure factor profiles indicates there is weak protein selfassociation, which is also apparent from rotational diffusion coefficient measurements.

More recently, Hung et al. measured the self-diffusion of a labelled mAb in a solution crowded by the unlabelled mAb using FCS across a range of solution conditions [23]. The protein-protein interactions were tuned from weakly attractive to hard-sphere like by using solubility enhancing excipients such as arginine chloride or imidazole [24]. In contrast to previous protein studies, the tracer protein is retarded less than expected based on the macroscopic viscosity, where the negative deviations to the GSE become more significant as the protein-protein attractions are mitigated. To explain this phenomenon, self-association between tracers was suggested to increase in more viscous formulations i.e. in $250 \mathrm{mM} \mathrm{NaCl}$ 
solutions as opposed to $0.1 \mathrm{M}$ imidazole solutions; however, this is in stark contrast to Roos et al. paper [8]. After implementing the Holyst model [18], Hung et al. found a correlation between Holyst's interaction parameter and the relative viscosity or the strength of the short range attractive protein-protein interactions derived from SAXS data using the Yukawa model. Finally, it should also be noted that the diffusion of a tracer particle in a concentrated protein solution may be anomalous as often suggested for transport in cells or in polymers [11] although caution should be taken as the origin of the anomalous behaviour may have a number of origins not related to the macromolecular transport itself such as change of refraction index.

Here, we move away from the recent Hung et al. work as FCS measurements are carried out to determine relative microviscosities using tracer molecules of different sizes in solutions with two different mAbs or BSA and compared against rheometry measurements. Previous studies suggest mAbs exhibit negative deviations to the GSE, while the GSE is applicable to globular proteins where the tracer and crowder are the same protein. It is not clear if the difference in behaviour between mAbs and globular proteins arises due to the differences in shape and size or due to effects of transient interactions between the protein molecules. In the present study, measurements are carried out over a range of solution conditions chosen to tune the protein self-association properties. We show that the FCS experiments demonstrate a clear effect of tracer size and observe a negative deviation from the GSE with the mAb solutions. However, in contrast to Hung et al. [23], we find GSE is applicable to $\mathrm{mAb}$ solutions in the limiting case of weakly attractive interactions between proteins, but negative deviations arise when there exists strong association between crowder proteins.

\section{Materials and Methods}

\section{Materials}

Two mAbs termed COE-03 (human IgGK, MW $144.8 \mathrm{kDa}, \mathrm{pl}=8.44$ ) and COE-19 (human $\operatorname{lgG1\lambda }$, MW 148 kDa, pl = 7.4) were kindly provided by Astra Zeneca (Cambridge, UK). Protein-protein interaction measurements for $\mathrm{COE}-03$ have been reported in Roberts et al. $[25,26]$. In Singh et al. [27] results are provided for COE-03 and for COE-19 (COE-03 is mAb1 and COE-19 is mAb2 in that study). 
ATTO-Rho6G, BSA-Alexa Fluor ${ }^{\mathrm{TM}} 488$ (BSA-AF), mouse IgG1 isotype control labelled with Alexa Fluor ${ }^{\mathrm{TM}} 488$ (IgG-AF) and mouse IgM isotype - custom labelled with Alexa Fluor ${ }^{\mathrm{TM}} 488$ by Thermo Fisher- (IgM-AF) were acquired from Thermo Fisher Scientific (Leicestershire, UK). 5-Tetramethylrhodamine labelled RRADDSDDDDD peptide (single letter amino acid code, termed hereafter 'TMR peptide') was obtained from Cambridge Bioscience (Cambridge, UK). Rhodamine Green ${ }^{\mathrm{TM}}$ was acquired from Invitrogen (Paisley, UK). Note that all tracers were chosen to have a charge of the same sign as the molecular crowder.

Lab-Tek Nunc ${ }^{\circledR}$ eight-well chamber slides, scintillation vials, toluene and sucrose were obtained from Fisher Scientific Ltd (Leicestershire, UK). BSA, buffer components and salts (acetic acid, sodium acetate, Tris, Tris. $\mathrm{HCl}$, sucrose, histidine, sodium thiocyanate, and sodium chloride) were acquired at analytical grade from Sigma Aldrich (Dorset, UK). All buffers (Table 1 ) and solutions were prepared with Millipore de-ionised water (18 M $2 . \mathrm{cm})$ and pre-filtered prior to experiments.

mAbs COE-03 and COE-19 were dialysed with 20 kDa molecular weight cut off (MWCO) Slide-A-Lyzer cassettes (Slide-A-Lyzer G2 cassette, 10,000 MWCO, Thermo Fisher Scientific, Leicestershire, UK, following the manufacturer's instructions) at $4^{\circ} \mathrm{C}$ from stock $\mathrm{pH} 6.0$ buffer ( $25 \mathrm{mM}$ Histidine, $205 \mathrm{mM}$ sucrose) to $\mathrm{pH} 5.0$ buffer ( $25 \mathrm{mM}$ ionic strength (IS) sodium acetate) for $\mathrm{COE}-03$ or directly into the target buffer for COE-19. mAb was concentrated with a $30 \mathrm{kDa}$ MWCO ultrafiltration membrane in a nitrogen pressurised Amicon stirred cell at $4^{\circ} \mathrm{C}$. The mAb solution was finally dialysed at $4^{\circ} \mathrm{C}$ overnight, with a typical exchange factor of 1000x, into the target experimental conditions described in Table 1. Protein preparations were filtered with 0.2 or $0.45 \mu \mathrm{m}$ syringe or centrifuge filters where possible. To monitor protein self-buffering, concentrated protein solution $\mathrm{pH}$ was measured with a semi-micro $\mathrm{pH}$ probe. In instances of $\mathrm{pH}$ shift from protein self-buffering where dialysis failed to correct this, buffer was reformulated to match and dilute the protein. Protein concentration was measured by UV absorption at $280 \mathrm{~nm}$ (Nanodrop 2000, Thermo Fisher Scientific, Leicestershire, UK) following a solution equilibration period of hours for reliable measurement (COE-03, $\varepsilon=1.435 \mathrm{mg} / \mathrm{ml}^{-1} \mathrm{~cm}^{-1}, \mathrm{pl} 8.44 ;$ COE-19, $\varepsilon=1.78 \mathrm{mg} / \mathrm{ml}^{-1} \mathrm{~cm}^{-1}, \mathrm{pl} 7.8$ ). BSA was first dissolved in buffer $\mathrm{pH} 7.0$ ( $8 \mathrm{mM}$ sodium acetate, $145 \mathrm{mM} \mathrm{NaCl}$ and $0.05 \mathrm{~g} / \mathrm{L}$ PS80) then dialysed with 20 kDa molecular weight cut off (MWCO) Slide-A-Lyzer cassettes (Slide-A-Lyzer G2 cassette, 10,000 MWCO, Thermo Fisher Scientific, Leicestershire, UK, 
following the manufacturer's instructions) at $4^{\circ} \mathrm{C}$ from stock $\mathrm{pH} 7.0$ (8 $\mathrm{mM}$ sodium acetate, $145 \mathrm{mM} \mathrm{NaCl}$ and $0.05 \mathrm{~g} / \mathrm{L} \mathrm{PS} 80$ ) to $\mathrm{pH} 7.0$ buffer ( $8 \mathrm{mM}$ sodium acetate, $145 \mathrm{mM} \mathrm{NaCl}$ and $0.05 \mathrm{~g} / \mathrm{L}$ PS80 with excipients i.e. sucrose $(250 \mathrm{mM})$ or Arg $(250 \mathrm{mM})$, Glu (250mM) or Arg$\mathrm{HCl}(250 \mathrm{mM}))$. BSA was concentrated with a $30 \mathrm{kDa}$ MWCO ultrafiltration membrane in a nitrogen pressurised Amicon stirred cell at $4^{\circ} \mathrm{C}$. The $\mathrm{pH}$ of the solutions was adjusted using sodium acetate (for acetate buffer) or hydrochloric acid (for TRIS and histidine buffers). Protein concentration was measured by UV absorption at $280 \mathrm{~nm}$ (Nanodrop 2000, Thermo Fisher Scientific, Leicestershire, UK) following a solution equilibration period of hours for reliable measurement $\left(\varepsilon=0.667 \mathrm{mg} / \mathrm{ml}^{-1} \mathrm{~cm}^{-1}\right)$.

\section{Fluorescence Correlation Spectroscopy (FCS)}

The experimental approach has been described elsewhere [28]. Briefly, the 488nm Argon laser line of a Zeiss Confocor2 LSM 510 META (Zeiss, Jena, Germany) and a 40x/1.2NA water-immersion objective was utilised. The laser beam waist, $\omega_{0}$, was determined by measuring Rhodamine Green ${ }^{\mathrm{TM}}$ experimental diffusion time, $\tau_{D}$, (33 $\left.\pm 5 \mu \mathrm{s}\right)$ then by using Equation 2 and a published diffusion coefficient of $2.8 \times 10^{-6} \mathrm{~cm}^{2} / \mathrm{s}$ [29]:

$$
\omega_{0}^{2}=4 D \tau_{D}
$$

where $\tau_{D}$ is the diffusion time, $\omega_{0}$ the laser beam waist and $D$ is the diffusion coefficient.

Samples were loaded in duplicate into the corner of Lab-Tek Nunc eight-well chamber slides (Fisher Scientific, Leicestershire, UK) and duplicate measurements collected. A constant volume of fluorescently labelled tracer was added to each mAb or BSA solution in order to have a constant number of fluorescent particles (in the region of 5 and 10 particles per focal volume depending on the experimental condition); care was taken so that the maximum tracer : protein ratio would be at the maximum 1:500 to avoid nucleation [30]. The $40 \mathrm{x} / 1.2 \mathrm{~W}$ NA collar was adjusted manually in order to minimize the change of the aforementioned number of particles per focal volume as described by Goins et al. [14]. Diffusion measurements were performed at least 40 times and the acquisition time was varied between $5 \mathrm{~s}$ and $60 \mathrm{~s}$ per run depending on the molecular crowder's concentration.

The correlation function $G(\tau)$ of the temporally changing fluorescence signal $I(t)$ for a single species is defined as: 
$G(\tau)=\frac{\langle\delta I(t) \delta I(t+\tau)\rangle}{\langle I(t)\rangle^{2}}$

For a three dimensional diffusion of a single species with triplet state correction $G(\tau)$ is given by

$G(\tau)=\left(1-T+T \exp \left(-\tau / \tau_{T}\right)\right) G_{D}(\tau)$

where $T$ is the triplet fraction and $\tau_{\top}$ is the triplet time

A single-exponential model was applied to fit the autocorrelation curve, $G_{D}(\tau)$ :

$G_{D}(\tau)=\frac{1}{N}\left(\frac{1}{1+\left(\tau / \tau_{D}\right)} \cdot \sqrt{\frac{1}{1+S^{2}\left(\tau / \tau_{D}\right)}}\right)$

where $N$ is the number of particles and $S$ is the structure parameter.

In complex media, diffusion is often described as being anomalous in which the mean square displacement, MSD, follows the following expression:

$M S D^{2}(t)=6 \Gamma t^{\alpha}$

Transforming Eq (2) to account for anomalous diffusion results in:

$G_{D}(\tau)=\frac{1}{N}\left(\frac{1}{1+\left(\tau / \tau_{D}\right)^{\alpha}} \cdot \sqrt{\frac{1}{1+S^{2}\left(\tau / \tau_{D}\right)^{\alpha}}}\right)$

When the anomalous coefficient, $\alpha$, is $<1$ it is termed subdiffusion; when it is $>1$, it is termed superdiffusion. The autocorrelation functions $G(\tau)$ were fitted using either the nonlinear least squares method of the fitting program OriginPro2015 (OriginLab, Northampton, MA) or the MEMFCS software QuickFit 3 [31].

\section{Viscosity measurements}

Vilastic. The Vilastic-3 Viscoelasticity Analyser (Vilastic Scientific, Inc., Austin, TX) was used. In Vilastic-3 experiments, the sample fills up a cylindrical measurement tube (radius $R=0.05$ $\mathrm{cm}$ and length $\mathrm{L}=6.4 \mathrm{~cm}$ ) and is forced to flow at a given oscillatory shear rate $\dot{\gamma}(\mathrm{t})=$ $\dot{\gamma}_{0} \sin (\omega \mathrm{t})$ with frequency $\omega$ by a coupling fluid. A sensor measures the pressure drop $\Delta \mathrm{P}(\mathrm{t})$ between the two ends of tube. A momentum balance relates $\Delta \mathrm{P}(\mathrm{t})$ to the in-phase and outof-phase components of the stress with the wall shear rate, $\tau^{\prime}(\omega)=\omega \eta^{\prime}\left(\dot{\gamma}_{0}\right)$ and $\tau^{\prime \prime}(\omega)=\omega \eta^{\prime \prime}$ $\left(\dot{\gamma}_{0}\right) . \quad \eta^{\prime}\left(\dot{\gamma}_{0}\right)$ and $\eta^{\prime \prime}\left(\dot{\gamma}_{0}\right)$ are the dynamic viscosity and "elasticity" respectively [32]. The dynamic viscosity of the IgG solutions was measured at a frequency of $1 \mathrm{~Hz}$ over a range of 
shear rates $\dot{\gamma}_{0}=1-100 \mathrm{~s}^{-1}$ at $25^{\circ} \mathrm{C} .2 \mathrm{ml}$ sample cups were used in order to load the samples, and the protein buffer was systematically chosen as the coupling fluid. Measurements were performed 100 times and the output was averaged and repeated in triplicate for each sample.

Rheochip. Shear viscosity measurements were performed using the in-house RheoChip platform. The RheoChip is a microfluidic rheometry device made of polymethyl methacrylate (PMMA) using soft lithographic methods to create three internal rectangular channels of widths $w_{c}=800,200$ and $100 \mu \mathrm{m}$ respectively and nominal height $h=50 \mu \mathrm{m}$. Channels are oxygen plasma treated to make them hydrophilic and protein adhesion resistant. All experiments are performed using the $200 \mu \mathrm{m}$ channel unless otherwise specified. The channel contains a pressure tap, at a distance from the inlet sufficient for one-dimensional, Poiseuille-like, laminar flow to be achieved. A second pressure tap is located $30 \mathrm{~mm}$ further along the channel. These pressure taps are each fitted with pressure detection unit consisting of two identical linear strain gauge pressure transducers, enabling the differential pressure drop across the length of channel between the taps to be measured. The RheoChip is calibrated using deionised water with known viscosity corresponding to the measured temperature during calibration. A calibration constant, $f$, is established for each chip, where

$f=\frac{1}{\left(\frac{\Delta P}{Q}\right)_{A v g}}$

Where $\Delta P$ is the differential pressure, $Q$ is the imposed flowrate and the Avg subscript reflects average over multiple shear rates. The RheoChip is filled with the solvent of the sample and allowed to reach steady state prior to measurement. A $1 \mathrm{~mL}$ glass syringe filled with protein sample is secured in a Nexus 6000 syringe pump (Chemyx, TX, USA) and connected to the RheoChip apparatus, ensuring there are no air bubbles in the system. The sample is pumped into the chip in a cycle of flowrates from $10 \mathrm{~mL} / \mathrm{hr}$ to $2 \mathrm{~mL} / \mathrm{hr}$ in increments of $2 \mathrm{~mL} / \mathrm{hr}$, each time allowing sufficient time for steady state flow to be achieved. The pressure drop across the channel at each flow rate is detected and relayed to a data acquisition platform consisting of National Instruments CompacDAQ 9172 chassis, a National Instruments 9237 data acquisition modulus and LabView software (National Instruments). 
For each imposed flow rate $Q$, the shear viscosity at the given shear rate $\dot{\gamma}=\frac{2 Q}{w_{c} h^{2}}$ is

$\eta(\dot{\gamma})_{\text {sample }}=f \cdot \eta_{H_{2} 0}\left(\frac{\Delta P}{Q}\right)_{\text {sample }}$

where $f$ and $\eta_{H_{2} 0}$ are the chip calibration constant and the viscosity of deionised water (respectively) at calibration temperature.

\section{$k_{D}$ measurements- Dynamic light scattering}

A Wyatt miniDAWN TREOS with an online QELS module was used for dynamic light scattering measurements (Wyatt Technology, Santa Barbara, CA). The instrument uses a GaAs laser at a wavelength of $658 \mathrm{~nm}$ at $90^{\circ}$. Measurements were made using a flow cell, with samples delivered using the Wyatt Calypso. The Calypso is a pumping and mixing system which uses three syringe pumps which can be programmed to generate precise concentration step gradients. The flow from each syringe pump is filtered through an inline $0.1 \mu \mathrm{m}$ membrane. Before entry to the flow cell, the individual streams are mixed by a static mixer.

In each experiment, the protein concentration was varied in equal step changes between 0.4 and $4 \mathrm{mg} / \mathrm{ml}$. All measurements were performed at $25^{\circ} \mathrm{C}$. Data analysis was performed using the Wyatt Technology ASTRA Software (version 6.1). The QELS instrument determines the hydrodynamic radius $\left(R_{h}\right)$ by measuring fluctuations in the light scattering intensity due to Brownian motion. The hydrodynamic radius is related to the diffusion coefficient using the Stokes-Einstein equation (see Equation (1)). Linear plots of the mutual diffusion coefficient $\left(D_{m}\right)$ obtained from a cumulants analysis method were plotted against concentration and the interaction parameter was calculated using the following relation

$D_{m}=D_{0}\left(1+k_{D} c\right)$

where $D_{0}$ is the diffusion coefficient at infinite dilution and $c$ is the protein concentration.

Values of $k_{D}$, which reflect effects of protein-protein interactions on the mutual diffusion coefficient, contain both thermodynamic and hydrodynamic contributions. $k_{\mathrm{D}}$ values greater than the excluded volume term indicate the net protein-protein interaction is repulsive, while lesser values indicate attractive protein-protein interactions. The excluded 
volume term is given by $k_{\mathrm{D}}^{\mathrm{ex}}=\left(k_{\mathrm{V}}^{\mathrm{ex}}-k_{\mathrm{H}}^{\mathrm{ex}}\right) V_{\mathrm{p}}$, where $V_{\mathrm{p}}$ is the protein volume in units of inverse protein concentration. $k_{\mathrm{V}}^{\mathrm{ex}}$ and $k_{\mathrm{H}}^{\mathrm{ex}}$ are the contributions from the thermodynamic and hydrodynamic terms, respectively. For spheres, $k_{\mathrm{v}}^{\mathrm{ex}}=8$ and $k_{\mathrm{H}}^{\mathrm{ex}}=6.55$. While proteins have anisotropic shapes, it has been shown that the thermodynamic term can be approximated by setting the protein volume equal to that of a sphere with the same hydrodynamic radius as the protein. If a similar assumption is made for the hydrodynamic term, for the $\mathrm{mAbs}, k_{\mathrm{D}}^{\mathrm{ex}} \approx 3.8 \mathrm{~mL} / \mathrm{g}$, which is based on a measured hydrodynamic radius $R_{\mathrm{H}}$ equal to $5.3 \mathrm{~nm}[26,27]$. For $\mathrm{BSA}$, using a value of $R_{\mathrm{H}}=3.7 \mathrm{~nm}[33]$ gives $k_{\mathrm{D}}^{\mathrm{ex}} \approx 3.0$ $\mathrm{mL} / \mathrm{g}$.

\section{Results and Discussion}

\section{Determination of protein-protein interactions}

Prior to measuring the microviscosity for a number of labelled tracers, protein-protein interactions were categorised as attractive or repulsive using the interaction parameter, $k_{D}$. The values of $k_{D}$ shown in Table 2 for COE-03 were taken from two previous studies $[25,26]$, while those for COE-19 and for BSA were measured here. The solution conditions for COE-03 were chosen such that the protein-protein interactions range from attractive to repulsive. The strongest attraction occurs in solutions at pH 9 followed by pH 5 with $250 \mathrm{mM} \mathrm{NaSCN}$, while there is a net protein-protein repulsion due to electrostatic double-layer forces in solutions at $\mathrm{pH} 5$ and to a lesser extent at $\mathrm{pH} 6.5$.

Adding $250 \mathrm{mM} \mathrm{NaCl}$ to the solution at pH 5 screens the electrostatic interactions and leads to a weak protein-protein attraction. The $k_{D}$ values for COE-19 reflect a much stronger selfassociation than observed for COE-03 under any solution condition [27]. On the other hand, the values of $k_{D}$ for BSA under all solution conditions investigated here are slightly greater than the excluded volume term indicating a weak net protein-protein repulsion. The results are consistent with the finding that human serum albumin, the human variant of BSA, does not exhibit any self-association in solutions at neutral pH values [34].

\section{Validation of the FCS method}

The potential of FCS to determine the relative macroscopic viscosity of sucrose $\left(R_{h} \sim 0.8 \mathrm{~nm}\right)$ solutions $(0.1-50 \% \mathrm{w} / \mathrm{w})$ was confirmed by comparing the ratio of the diffusion times 
obtained by FCS for a small molecule tracer (ATTO-Rho6G, $R_{h} \sim 0.6 \mathrm{~nm}$ ) and a large molecule tracer (IgG-AF, $R_{h} \sim 5.5 \mathrm{~nm}$ ) with the relative macroscopic viscosity measured using a rheometer Vilastic-3 (Figure 1). Excellent agreement between the relative macroviscosity and the ratio of the diffusion times or relative microviscosity is observed, with no effect of tracer size, confirming that the GSE relation (Eq. (1)) holds as $D \eta=D_{0} \eta_{0}$ for tracers much larger than the crowding molecule [16].

The diffusion of different fluorescently labelled tracers e.g. IgG-AF and ATTO-Rho6G was measured in mAb solutions. Figure 2 presents a typical example of the variation in the normalised autocorrelation curve for IgG-AF in the $\mathrm{pH} 5$ solution with increasing concentration of COE-03. A clear increase of the diffusion time of IgG-AF is observed with increasing $\mathrm{COE}-03$ concentrations, indicating retardation occurs during passive transport of IgG-AF in mAb solutions of increasing concentration.

\section{Setting concentration limits of the study}

All data were fitted with Equation (7) to check for anomalous diffusion, which has been related to molecular crowding [35], associated with the shape of the molecular crowder (in that case BSA and $\lg G$ ) [10], linked to refractive index mismatch in single focus FCS [36], transient binding between crowder and tracer [37], and observed using FCS for high concentration protein solutions [11]. The diffusion was considered anomalous when, based on literature $[14,38,39]$, the anomalous coefficient, $\alpha$, was found to be less than 0.8 and a clear concentration dependence towards strong anomalous behaviour (i.e. less than 0.7) was observed although strictly speaking, $\alpha<1$ indicates anomalous diffusion. For most experimental conditions (see Figure S1), there is no definitive pattern due to the uncertainty in the parameter estimation. However, for solutions of COE-03 at pH 9 there is a significant reduction in $\alpha$ at the highest protein concentrations (i.e. $195 \mathrm{~g} / \mathrm{L}$ ). At this concentration, the behaviour was considered anomalous and the corresponding measurements with IgG-AF and Atto-Rho6G were not considered further in this work: the concentration limit for this condition was fixed at $150 \mathrm{~g} / \mathrm{L}$. The maximum concentration of COE-19 at pH 5 (without any $\mathrm{NaCl}$ ) was limited to $115 \mathrm{mg} / \mathrm{mL}$ as higher concentration samples became too viscous to handle. 


\section{Effect of tracer size on the microviscosity}

The influence of the tracer size on the ratio of diffusion times (or relative microviscosity) in protein solutions is assessed (Figure 3) and compared to the relative macroviscosities observed for solutions containing mAbs or BSA. In solutions crowded with BSA (Figure 3a), the effect of tracer size (TMR peptide vs BSA-AF) is not apparent in solutions up to BSA concentrations of $200 \mathrm{~g} / \mathrm{L}$ due to the limited change in viscosity. The effect of excipient type (e.g. sucrose versus arginine salts) on the diffusion time of either tracer was negligible compared to the effects of BSA concentration or tracer size, particularly for BSA concentrations $\geq 150 \mathrm{~g} / \mathrm{L}$ (Figure S2). The relative BSA-AF microviscosity appears to closely match the variation of the relative macroviscosity.

In mAb solutions (COE-03 and COE19 solutions) and in contrast with BSA, FCS derived microviscosities were strongly affected by tracer size (Figure $3 \mathrm{~b}$ and c). The 2 to 3 fold increase in retardation of the small molecule tracer, ATTO-Rho6G, when increasing concentration from 1 to $160 \mathrm{mg} / \mathrm{ml}$ was unaffected by solution conditions (Figure S2). In comparison, the microviscosities obtained under the same solution condition for IgG-AF and $\operatorname{lgM}-\mathrm{AF}$ increased by a factor of between 10 and 20 , and, IgM-AF is usually more retarded than IgG-AF. This visible size effect may be partially related to the more favourable ratio of sizes between ATTO-Rho6G and mAbs compared to TMR-peptide and BSA. For COE-19 solution concentrations $\geq 50 \mathrm{~g} / \mathrm{L}$ at $\mathrm{pH} 5$, diffusion of IgG-AF became less retarded upon addition of $250 \mathrm{mM} \mathrm{NaCl}$; high ionic strength dominated IgG-AF diffusion time over buffer pH, with data for pH $5250 \mathrm{mM} \mathrm{NaCl}$, pH $6.5250 \mathrm{mM} \mathrm{NaCl}$ and pH $8250 \mathrm{mM} \mathrm{NaCl}$ overlapping. In the case of COE-03, at concentrations $<150 \mathrm{~g} / \mathrm{L}$, the effect of high ionic strength or increasing buffer pH had little effect on IgG-AF diffusion times (Fig S2).

\section{Limitations of the hard sphere protein model is revealed using tracers of different sizes}

The aforementioned results are compared against the ratio of diffusion times for hard spheres (HS) to decouple the effects of crowding, attractive protein-protein interactions and anisotropic shape. The ratio of the diffusion times is calculated using the formula for describing long-time self-diffusion coefficients derived by van Blaaderen et al. [40] and used by others in similar studies [8, 24]: 
$\frac{\tau_{D, H S}}{\tau_{D, 0}}=\frac{\left(1+1.5 \phi+2 \phi^{2}+3 \phi^{3}\right)}{(1-\phi)^{3}}$

where $\phi$ is the equivalent hard sphere volume fraction $\left(\phi=N_{A} V c / M W_{h}\right), c$ is the protein concentration $(\mathrm{mg} / \mathrm{mL}), N_{A}$ is Avogadro's number, $V$ is an equivalent spherical volume of the protein, and $M W_{h}$ is the hydrated molecular weight of the protein [41].

A key question is what equivalent sphere size should be used to represent a protein with an anisotropic shape. Here, we follow the work by Hung et al. [24] where the equivalent spherical mAb volumes were determined from fitting osmotic compressibility data determined by light scattering to the interacting hard sphere model derived by Minton [42]. This approach gave a value for the sphere radius equal to approximately $4.6 \mathrm{~nm}$, which is used here for either mAb. BSA is represented by a sphere with radius equal to $3.4 \mathrm{~nm}$, which provides the best fit of a hard sphere virial equal of state to osmotic pressure data for BSA up to protein concentrations greater than $400 \mathrm{~g} / \mathrm{L}[34,43]$.

The measured retardation factors are almost equal to or just slightly greater than the hard sphere predictions shown by the solid line in Figure 3a. The results are consistent with the study by Roos et al. [8], where the hard sphere model accurately matched the FCSdetermined self-diffusion coefficients for labelled BSA in a solution crowded with BSA. In that study, the equivalent hard sphere radius was treated as an adjustable parameter by fitting a factor $\kappa$ to relate the equivalent spherical volume fraction $\phi_{\mathrm{HS}}$ to the actual protein volume fraction, $\phi$, according to $\phi_{\mathrm{HS}}=\kappa \phi$. For BSA, the fit value of $\kappa=2.1$ corresponds to a sphere with radius equal to $3.4 \mathrm{~nm}$, which is the same as the value used in our work. The molecular basis for why the parameter $\kappa$ is greater than 1 is different in our work: Roos et al. [8] indicate the parameter is required to account for the weak protein self-association that was observed from fitting to structure factor profiles measured under ultra-low ionic strength conditions. Here, the value $\kappa$ is not an adjustable parameter, but rather derived from the best fit to concentrated-solution thermodynamic data for BSA obtained in solutions at $\mathrm{pH} 7.4$ and $150 \mathrm{mM} \mathrm{NaCl}[34,43]$. When fitting the compressibility data to a spherical model, the effective volume fraction is different from the BSA partial specific volume due to the anisotropic shape of the molecule and due to weak electrostatic repulsions [34]. Both of these factors will cause the effective spherical volume to increase. 
For COE-03 and for COE-19, the ratio of diffusion times measured when using the IgG-AF probe is always greater than the predictions of the hard sphere model. The increased retardation follows the same pattern of behaviour with respect to protein-protein interactions as observed in Hung et al. [23]. In that study, the hard sphere-like behaviour was approached only under solution conditions with added excipients that weaken protein self-association. Here we find the largest deviations observed for COE-03 and for COE-19 occur under solution conditions where protein-protein attractions are the strongest.

\section{Modelling of protein behaviours}

To provide a quantitative comparison between the micro- and macro-viscosity data (Figure 3), the model of protein viscosity behaviour previously adopted by Connolly et al. [44], was used to describe the retardation of diffusion and the change of viscosity as outlined in Equations (12) and (13). Although Holyst model [18] was also considered (see Supplementary Information), Connolly's approach is simpler and provide similar information. In their work, the protein concentration dependence of the viscosity was parametrised by the exponential coefficient $(k)$ of a simple exponential model.

$\eta=\eta_{0} e^{k c}$

where $k$ is the exponential coefficient. Assuming the Stokes Einstein relation applies:

$\tau_{D}=\tau_{D, 0} e^{k c}$

$k$-values determined using Equations (12) and (13) for both mAb and BSA solutions are summarised in Table 3. Initially, the $k$-value was used to compare the difference between FCS and rheology data.

Model protein solutions. In BSA solutions TMR peptide derived $k$-values are always significantly smaller than both RheoChip and BSA-AF $k$-values and these are independent of the experimental condition (Tables 3 and 4). BSA-AF derived $k$-values indicate the microviscosity only results in a slightly negative deviation from the GSE in presence of sucrose; as the GSE holds for ArgGlu and ArgHCl, the limited difference between the hard sphere relative diffusion times and the experimental ones suggest BSA can be viewed as a hard sphere protein (Figure 3a and Table 3). Furthermore Roos et al. BSA data obtained in 
absence of buffer concur to our data (both FCS and RheoChip as seen Figure S3) confirming the limited influence of co-solutes on BSA diffusional behaviour. In fact, the three proteins they studied i.e. lysozyme, BSA and $\alpha$ B-crystalline (using NMR and/or FCS) followed the GSE [8]; $\alpha$-crystallin and BSA are known to behave like globular hard sphere model proteins [4547] or at least to a certain extent [48].

Importance of size in mAb solutions. Overall, in mAb solutions, $k$-values for ATTO-Rho6G (a much smaller tracer than IgG-AF) are significantly smaller than those obtained with Rheochip, IgG-AF- or IgM-AF-FCS derived data (see Tables 3 and 4), and, insignificantly affected by the experimental conditions, reflecting the relatively small increase in the microviscosities observed experimentally (Figure S2). The behaviour of ATTO-Rho6G in mAb solutions is expected as the tracer should be a similar size to or greater than the crowder for the GSE to be applicable [16]. When the crowder becomes much larger than the tracer, the tracer diffusion times become much less dependent on the viscosity. The dye (ATTO-Rho6G) behaves somewhere between a tracer of the crowder's size, IgG-AF and small molecules, such as dioxane. Roos et al showed that dioxane experienced the viscosity of a near-pure solvent solution, because crowding proteins appeared as quasi-static objects on the time scale of translational diffusion [5] .

For COE-03 $(\mathrm{pH} \mathrm{6.5)}$ and COE-19 $(\mathrm{pH} 6.5250 \mathrm{mM} \mathrm{NaCl})$, the variation of the IgM-AF ratio of diffusion times matches the evolution of the relative viscosity determined using the Rheochip indicating the GSE holds for these experimental conditions (Figure $3 \mathrm{~b}$ and $\mathrm{c}$ ). This is consistent with a previous study showing the macroviscosity is obtained using tracers between two and four times the size of the PEG crowder [18]. However, IgM-AF experimental diffusion times were strongly influenced by buffer conditions. For other conditions (i.e. $\mathrm{pH} 8250 \mathrm{mM} \mathrm{NaCl}$ or $\mathrm{pH} 5$ for $\mathrm{COE}-19$ ), this close relation between microviscosity and macroviscosity is not true as a positive deviation from the GSE is observed [16]. This non-ideal behaviour cannot be ascribed to anomalous diffusion, since the values for $\alpha$ in either condition remained between 0.9 and 1.0 (Figure S1). The positive deviations from the GSE are likely due to interactions of the tracer with the crowder protein as already reported for gold nanoparticles, wherein Brownian diffusion of the nanoparticles was altered by their adsorption to BSA [49]. Rothe and al. [5] observed a positive deviation in mixtures of $\mathrm{BSA}$ and $\mathrm{SH} 3$ which were attributed to inter protein interactions and/or 
concentration dependent binding as shown by isothermal calorimetry and a potential clustering of BSA. Similarly, positive deviations from the GSE observed when using apomyoglobulin as a tracer particle in solutions of either RNAse A or BSA, were suggested to be related to the presence of nonspecific (e.g. electrostatic) crowder-tracer interactions [22, 50], which also provides the likely explanation for the retardation of chymotrypsin inhibitor diffusion in protein solutions [51] . Overall IgM-AF may be an unreliable tool to use to evaluate the viscosity of a solution in absence of additional information such as charge of the proteins.

\section{IgG-AF vs Rheochip}

$\boldsymbol{k}$ appears to be only affected by attractive conditions. $k$-values (Table 3 ) from FCS and RheoChip were graphed in Figure 4. A correlation between FCS and RheoChip derived data is observed although FCS derived $k$-values increase is limited compared to RheoChip derived data for attractive conditions. Overall, Figure 4 and Table 4 indicate: i) the ordering of the conditions according to the viscosity obtained by FCS and Rheochip is similar (i.e. $k$-values for COE-03 pH 9> pH $6.5 \sim$ pH $5250 \mathrm{mM} \mathrm{NaSCN}>$ pH $5 \sim$ pH $5250 \mathrm{mM} \mathrm{NaCl}$ and for COE-19 pH $5>$ pH $6.5250 \mathrm{mM} \mathrm{NaCl} \geq \mathrm{pH} 5250 \mathrm{mM} \mathrm{NaCl} \geq \mathrm{pH} 8250 \mathrm{mM} \mathrm{NaCl}$ ). A key difference between $\mathrm{COE}-03$ and $\mathrm{COE}-19$ is that the interactions are much more attractive (see Table 2) for COE-19 except for the $\mathrm{pH} 9$ conditions for COE-03. Perhaps a better way is to correlate the exponential coefficient, $k$, to the protein-protein diffusion interaction parameter, $k_{\mathrm{D}}$ (see equation (10)) as did Conolly et al. [44]

For our IgG-AF FCS- and RheoChip- derived data as well as the pairs $\left(k, k_{D}\right)$ adapted from Conolly et al.[44], Figure 5 suggests, rather than being a linear relation between the two parameters as suggested by Conolly et al., a more complex relation exists, perhaps based on an exponential decay between $k$ and $k_{D}$. Indeed, $k$-values decrease from strongly attractive conditions to repulsive conditions. It is also noticeable that this apparent relation is stronger with the RheoChip derived data than with our FCS derived data (Figure 5) suggesting selfdiffusion may be less sensitive to attractive conditions than the viscosity.

Breakdown of the GSE. $k$-values (Tables 3 and 4) from FCS and RheoChip indicate i) for BSA, the BSA-AF relative microviscosities match the relative macroscopic viscosity for ArgGlu and $\mathrm{ArgHCl}$ and behave differently for sucrose ii) for $\mathrm{COE}-03$, IgG-AF relative microviscosities 
match the relative macroviscosity for $\mathrm{pH} 6.5, \mathrm{pH} 5250 \mathrm{mM} \mathrm{NaCl}$ and $\mathrm{pH} 5250 \mathrm{mM} \mathrm{NaSCN}$. The only clear difference (based on data Table 4) is at $\mathrm{pH} 9$ which corresponds to the most viscous solution where there is strong reversible association. In this case a negative deviation from the GSE is observed; iii) for COE-19, in all cases FCS derived $k$-values are significantly lower than RheoChip derived $k$-values.

Thus, the GSE seems to hold for labelled BSA in BSA solutions as observed by Roos et al. [8] (see Figure S3). The negative deviations from GSE $\left(k_{F C S}<k_{\text {RheoChip }}\right.$ and Figure 4$)$ occur for solution conditions corresponding to the lowest values for the interaction parameter, $k_{\mathrm{D}}$, indicating the diffusion of IgG-AF is slowed down in the presence of attractive proteinprotein interactions (i.e. for COE-19, in all cases FCS derived $k$-values are significantly lower than Rheochip derived $k$-values). As such, microviscosity predictions underestimate macroviscosity where there is strong self-association between the crowder proteins. This is supported when comparing the experimental $k$-values to the hard-sphere derived values (Table 3) indicating greater deviations from HS behaviour for COE-19 especially when electrostatic interactions are not screened ( $\mathrm{pH} 5$ for COE-19). Conversely, the relative microviscosity obtained from FCS is similar to the relative macroviscosity for COE-03 under all solution conditions except for $\mathrm{pH} 9$.

Negative deviations from the GSE when using a tracer protein with similar size to the crowder protein have only been reported in Hung et al. [23] for a solution containing the same mAb as a crowder and as a tracer (except the tracer was labelled). In that study, solution conditions were chosen to mitigate the amount of self-association. In contrast to our study, the negative deviations occur in the opposite limit of reducing the self-association when adding solubility enhancing excipients, while the GSE is applicable under conditions with weak self-association.

A key question is why have negative deviations not been observed in other studies of protein solutions. Most studies on the applicability of the GSE have been carried out under very low ionic strength conditions, where interactions between crowder molecules are dominated by long-ranged electrostatic repulsions $[5,8,16]$. The only exception is the study by Zorilla et al. [22] where the GSE was tested under physiological salt conditions (150 mM $\mathrm{NaCl}, 20 \mathrm{mM}$ phosphate, $\mathrm{pH}$ 7.4) using either HSA or RNase A as crowders. Under these 
solution conditions, the behaviour of HSA is well represented using only excluded volume interactions reflecting the absence of any self-association [34, 42]. In addition, a selfinteraction chromatography study of RNase A found that protein-protein interactions are net repulsive, as characterized in terms of the osmotic second virial coefficient $B_{22}$, at pH 6.5 and at $\mathrm{pH} 8.0$ in solutions with sodium chloride concentrations greater than $100 \mathrm{mM}$ [52]. Hung et al. suggest the association state controls the tracer's size of tracer but not crowder's; to hold this would indicate that (1) interactions between probe molecule and COE-19 are weaker than interactions between probe molecule and COE-03 and (2) interactions between probe molecule and $\mathrm{COE}-03$ are weakest at $\mathrm{pH} 9$ and no salt. In contrast, our results indicate the solution conditions exhibiting negative deviations to the GSE correspond to when interactions are stronger rather than weaker since all antibodies have high $\mathrm{pl}$ values and strongest attractions usually occur under these conditions. According to our previous study, we expect the values of $B_{22}$ to be less than zero for these conditions, indicating the presence of a protein-protein attraction that is greater in magnitude than the excluded volume contribution to $B_{22}$. As such, we hypothesize that negative deviations occur due to strong self-association between crowder molecules. If crowder molecules bind transiently to each other, the ratio of crowder size to tracer size increases. According to the Holyst model and the work by Muramatsu and Minton, an increase in the size ratio causes a decrease in the tracer particle retardation factor leading to the negative deviations to the GSE. The key assumption is that the interactions between the tracer and crowder IgGs are less attractive than the crowder IgG self-interactions. There is some evidence to suggest this is the case at least for the conditions tested with COE-19. In our previous study [27], we showed that the self-interactions for COE-19 are more attractive than the cross interaction between COE-03 and COE-19 over a range of $\mathrm{pH}$ and ionic strength values.

In the study by Hung et al. [23], the strongest self-association between crowder IgG corresponded to conditions where the value of $B_{22}$ normalized by the excluded volume term is equal to -0.2 . This value indicates only slightly less attractive conditions than for COE-03 at $\mathrm{pH}$ 9, where we observe the negative deviations. At this stage it is not possible to hypothesize why there exists this discrepancy, in particular because the GSE applicability depends sensitively on the crowder-tracer interactions. The negative deviations observed 
by Hung et al. [15] arise in solutions with solubility enhancing excipients which weaken the crowder self-association as well as any association between crowder and tracer. On the other hand, we expect our negative deviations arise when increasing the association between the crowder molecules relative to the crowder-tracer cross interaction.

\section{Conclusion}

In this work, we have considered whether Fluorescence Correlation Spectroscopy could be a suitable tool to determine protein viscosity based on the General Stokes Einstein relation. To this effect, the diffusion of fluorescent tracers of like charge to the crowder protein but with different sizes was measured in protein solutions.

Similarly to what has been observed in polymers [17] and recently in IgG solutions [53], a size effect is observed in protein solutions as shown by $k$-values indicating that microviscosities of tracers (AttoRho6G or TMR-peptide) smaller than the crowding protein (mAb or BSA) systematically underpredict the macroviscosity (resulting in a so-called negative deviation from the GSE). In presence of a tracer whose size is similar to the crowding protein (e.g. IgG-AF for mAbs), negative deviations from the GSE are observed in presence of strongly attractive conditions between the crowder molecules (all COE-09 experimental conditions) suggesting this behaviour may be related to the crowder's selfassociation. However, this breakdown of the GSE disappears in solution conditions where interactions between crowding proteins are repulsive or only weakly attractive (e.g. IgG-AF in $\mathrm{COE}-03$ and BSA-AF in BSA). The experimental deviation from hard sphere ratios of diffusion times highlights the importance of attractive protein-protein interactions. This is further shown with an apparent relation between the exponential parameter, $k$, and the interaction parameter, $k_{D}$, indicating strong attractive interactions are more likely to affect viscosity and the GSE relation. A key question remaining is whether or not there are any interactions between tracer and crowder molecules. Indeed, for studies involving tracers, the charge of the tracer, its concentration or its size should be carefully considered to mitigate these issues as, for example, the largest tracer, IgM-AF, behaviour was less predictable in strongly attractive conditions (e.g. $\mathrm{COE}-19$ at $\mathrm{pH} 5$ ) which ultimately lead to interactions between tracer and mAbs. 
Acknowledgments: PD was funded by MedImmune/Astra Zeneca, DC and AL were partfunded by MedImmune/Astra Zeneca and BBSRC, MS was funded by a BBSRC BRIC award supported by MedImmune/Astra Zeneca, NS was funded by a BBSRC CASE award supported by MedImmune/Astra Zeneca, AR funded by a project part of the EU Horizon 2020 Research and Innovation program under the Marie Skłodowska-Curie grant agreement No 675074. 
References

reference

[1] A. Saluja, D.S. Kalonia, Nature and consequences of protein-protein interactions in high protein concentration solutions, International Journal of Pharmaceutics 358 (2008) 1-15.

[2] H.-X. Zhou, G. Rivas, A.P. Minton, Macromolecular crowding and confinement: Biochemical, biophysical, and potential physiological consequences, Annual Review of Biophysics2008, pp. 375397.

[3] S. Yadav, S.J. Shire, D.S. Kalonia, Viscosity Analysis of High Concentration Bovine Serum Albumin Aqueous Solutions, Pharmaceutical Research 28 (2011) 1973-1983.

[4] S. Yadav, S.J. Shire, D.S. Kalonia, Viscosity behavior of high-concentration monoclonal antibody solutions: Correlation with interaction parameter and electroviscous effects, Journal of Pharmaceutical Sciences 101 (2012) 998-1011.

[5] M. Rothe, T. Gruber, S. Groeger, J. Balbach, K. Saalwaechter, M. Roos, Transient binding accounts for apparent violation of the generalized Stokes-Einstein relation in crowded protein solutions, Physical Chemistry Chemical Physics 18 (2016) 18006-18014.

[6] N. Muramatsu, A.P. Minton, TRACER DIFFUSION OF GLOBULAR-PROTEINS IN CONCENTRATED PROTEIN SOLUTIONS, Proceedings of the National Academy of Sciences of the United States of America 85 (1988) 2984-2988.

[7] M. Roos, S. Link, J. Balbach, A. Krushelnitsky, K. Saalwaechter, NMR-Detected Brownian Dynamics of alpha B-Crystallin over a Wide Range of Concentrations, Biophysical Journal 108 (2015) 98-106.

[8] M. Roos, M. Ott, M. Hofmann, S. Link, E. Roessler, J. Balbach, A. Krushelnitsky, K. Saalwaechter, Coupling and Decoupling of Rotational and Translational Diffusion of Proteins under Crowding Conditions, Journal of the American Chemical Society 138 (2016) 10365-10372.

[9] S. Amin, C.A. Rega, H. Jankevics, Detection of viscoelasticity in aggregating dilute protein solutions through dynamic light scattering-based optical microrheology, Rheologica Acta 51 (2012) 329-342.

[10] J. Balbo, P. Mereghetti, D.-P. Herten, R.C. Wade, The Shape of Protein Crowders is a Major Determinant of Protein Diffusion, Biophysical Journal 104 (2013) 1576-1584.

[11] D.S. Banks, C. Fradin, Anomalous diffusion of proteins due to molecular crowding, Biophysical Journal 89 (2005) 2960-2971.

[12] R. Ghosh, S. Sharma, K. Chattopadhyay, Effect of Arginine oil Protein Aggregation Studied by Fluorescence Correlation Spectroscopy and Other Biophysical Methods, Biochemistry 48 (2009) $1135-1143$.

[13] D.V. Gulnov, E.V. Nemtseva, V.A. Kratasyuk, Contrasting relationship between macro- and microviscosity of the gelatin- and starch-based suspensions and gels, Polymer Bulletin 73 (2016) 3421-3435.

[14] A.B. Goins, H. Sanabria, M.N. Waxham, Macromolecular Crowding and Size Effects on Probe Microviscosity, Biophysical Journal 95 (2008) 5362-5373.

[15] R.N. Zia, J.F. Brady, Microviscosity, microdiffusivity, and normal stresses in colloidal dispersions, Journal of Rheology 56 (2012) 1175-1208.

[16] Y.Q. Wang, C.G. Li, G.J. Pielak, Effects of Proteins on Protein Diffusion, Journal of the American Chemical Society 132 (2010) 9392-9397.

[17] R. Holyst, A. Bielejewska, J. Szymanski, A. Wilk, A. Patkowski, J. Gapinski, A. Zywocinski, T. Kalwarczyk, E. Kalwarczyk, M. Tabaka, N. Ziebacz, S.A. Wieczorek, Scaling form of viscosity at all length-scales in poly(ethylene glycol) solutions studied by fluorescence correlation spectroscopy and capillary electrophoresis, Physical Chemistry Chemical Physics 11 (2009) 9025-9032. 
[18] T. Kalwarczyk, K. Sozanski, A. Ochab-Marcinek, J. Szymanski, M. Tabaka, S. Hou, R. Holyst, Motion of nanoprobes in complex liquids within the framework of the length-scale dependent viscosity model, Advances in Colloid and Interface Science 223 (2015) 55-63.

[19] D. Lavalette, M.A. Hink, M. Tourbez, C. Tetreau, A.J. Visser, Proteins as micro viscosimeters: Brownian motion revisited, European Biophysics Journal with Biophysics Letters 35 (2006) 517-522. [20] A.J. Banchio, J. Bergenholtz, G. Nagele, Rheology and dynamics of colloidal suspensions, Physical Review Letters 82 (1999) 1792-1795.

[21] P.N. Segre, S.P. Meeker, P.N. Pusey, W.C.K. Poon, VISCOSITY AND STRUCTURAL RELAXATION IN SUSPENSIONS OF HARD-SPHERE COLLOIDS, Physical Review Letters 75 (1995) 958-961.

[22] S. Zorrilla, M.A. Hink, A.J.W.G. Visser, M.P. Lillo, Translational and rotational motions of proteins in a protein crowded environment, Biophysical Chemistry 125 (2007) 298-305.

[23] J.J. Hung, W.F. Zeno, A.A. Chowdhury, B.J. Dear, K. Ramachandran, M.P. Nieto, T.Y. Shay, C.A. Karouta, C.C. Hayden, J.K. Cheung, T.M. Truskett, J.C. Stachowiak, K.P. Johnston, Self-diffusion of a highly concentrated monoclonal antibody by fluorescence correlation spectroscopy: insight into protein-protein interactions and self-association, Soft Matter 15 (2019) 6660-6676.

[24] J.J. Hung, B.J. Dear, C.A. Karouta, A.A. Chowdhury, P.D. Godfrin, J.A. Bollinger, M.P. Nieto, L.R. Wilks, T.Y. Shay, K. Ramachandran, A. Sharma, J.K. Cheung, T.M. Truskett, K.P. Johnston, ProteinProtein Interactions of Highly Concentrated Monoclonal Antibody Solutions via Static Light Scattering and Influence on the Viscosity, Journal of Physical Chemistry B 123 (2019) 739-755.

[25] D. Roberts, R. Keeling, M. Tracka, C.F. van der Walle, S. Uddin, J. Warwicker, R. Curtis, Specific Ion and Buffer Effects on Protein-Protein Interactions of a Monoclonal Antibody, Molecular Pharmaceutics 12 (2015) 179-193.

[26] D. Roberts, R. Keeling, M. Tracka, C.F. van der Walle, S. Uddin, J. Warwicker, R. Curtis, The Role of Electrostatics in Protein-Protein Interactions of a Monoclonal Antibody, Molecular Pharmaceutics 11 (2014) 2475-2489.

[27] P. Singh, A. Roche, C.F. Van der Walle, S. Uddin, J. Du, J. Warwicker, A. Pluen, R. Curtis, Determination of Protein-Protein Interactions in a Mixture of Two Monoclonal Antibodies, Molecular Pharmaceutics 16 (2019) 4775-4786.

[28] Z. Hamrang, A. Pluen, E. Zindy, D. Clarke, Raster image correlation spectroscopy as a novel tool for the quantitative assessment of protein diffusional behaviour in solution, Journal of Pharmaceutical Sciences 101 (2012) 2082-2093.

[29] K. Bacia, P. Schwille, A dynamic view of cellular processes by in vivo fluorescence auto- and cross-correlation spectroscopy, Methods 29 (2003) 74-85.

[30] M.K. Quinn, N. Gnan, S. James, A. Ninarello, F. Sciortino, E. Zaccarelli, J.J. McManus, How fluorescent labelling alters the solution behaviour of proteins, Physical Chemistry Chemical Physics 17 (2015) 31177-31187.

[31] J.W.K.a.J. Langowski, QuickFit 3.0 (status: beta, compiled: 2015-10-29, SVN: 4465): A data evaluation application for biophysics, 2015.

[32] G.B. Thurston, ELASTIC EFFECTS IN PULSATILE BLOOD-FLOW, Microvascular Research 9 (1975) 145-157.

[33] N. Meechai, A.M. Jamieson, J. Blackwell, Translational diffusion coefficients of bovine serum albumin in aqueous solution at high ionic strength, Journal of Colloid and Interface Science 218 (1999) 167-175.

[34] P. Sonderby, J.T. Bukrinski, M. Hebditch, G.H.J. Peters, R.A. Curtis, P. Harris, Self-Interaction of Human Serum Albumin: A Formulation Perspective, Acs Omega 3 (2018) 16105-16117.

[35] N. Malchus, M. Weiss, Elucidating Anomalous Protein Diffusion in Living Cells with Fluorescence Correlation Spectroscopy-Facts and Pitfalls, Journal of Fluorescence 20 (2010) 19-26.

[36] S. Lehmann, S. Seiffert, W. Richtering, Refractive Index Mismatch Can Misindicate Anomalous Diffusion in Single-Focus Fluorescence Correlation Spectroscopy, Macromolecular Chemistry and Physics 216 (2015) 156-163. 
[37] H. Sanabria, M.N. Waxham, Transient Anomalous Subdiffusion: Effects of Specific and Nonspecific Probe Binding with Actin Gels, Journal of Physical Chemistry B 114 (2010) 959-972.

[38] I. Nardecchia, M. Lechelon, M. Gori, I. Donato, J. Preto, E. Floriani, S. Jaeger, S. Mailfert, D. Marguet, P. Ferrier, M. Pettini, Detection of long-range electrostatic interactions between charged molecules by means of fluorescence correlation spectroscopy, Physical Review E 96 (2017).

[39] R. Rashid, S.M.L. Chee, M. Raghunath, T. Wohland, Macromolecular crowding gives rise to microviscosity, anomalous diffusion and accelerated actin polymerization, Physical Biology 12 (2015).

[40] A. Vanblaaderen, J. Peetermans, G. Maret, J.K.G. Dhont, LONG-TIME SELF-DIFFUSION OF SPHERICAL COLLOIDAL PARTICLES MEASURED WITH FLUORESCENCE RECOVERY AFTER PHOTOBLEACHING, Journal of Chemical Physics 96 (1992) 4591-4603.

[41] A.D. Goncalves, C. Alexander, C.J. Roberts, S.G. Spain, S. Uddin, S. Allen, The effect of protein concentration on the viscosity of a recombinant albumin solution formulation, RSC Adv. 6 (2016) 15143-15154.

[42] A.P. Minton, Static light scattering from concentrated protein solutions, I: General theory for protein mixtures and application to self-associating proteins, Biophysical Journal 93 (2007) 13211328.

[43] V.L. Vilker, C.K. Colton, K.A. Smith, THE OSMOTIC-PRESSURE OF CONCENTRATED PROTEIN SOLUTIONS - EFFECT OF CONCENTRATION AND PH IN SALINE SOLUTIONS OF BOVINE SERUMALBUMIN, Journal of Colloid and Interface Science 79 (1981) 548-566.

[44] B.D. Connolly, C. Petry, S. Yadav, B. Demeule, N. Ciaccio, J.M.R. Moore, S.J. Shire, Y.R. Gokarn, Weak Interactions Govern the Viscosity of Concentrated Antibody Solutions: High-Throughput Analysis Using the Diffusion Interaction Parameter, Biophysical Journal 103 (2012) 69-78.

[45] G. Foffi, G. Savin, S. Bucciarelli, N. Dorsaz, G.M. Thurston, A. Stradner, P. Schurtenberger, Hard sphere-like glass transition in eye lens alpha-crystallin solutions, Proceedings of the National Academy of Sciences of the United States of America 111 (2014) 16748-16753.

[46] M. Heinen, F. Zanini, F. Roosen-Runge, D. Fedunova, F. Zhang, M. Hennig, T. Seydel, R. Schweins, M. Sztucki, M. Antalik, F. Schreiber, G. Naegele, Viscosity and diffusion: crowding and salt effects in protein solutions, Soft Matter 8 (2012) 1404-1419.

[47] P. Vodnala, N. Karunaratne, L. Lurio, G.M. Thurston, M. Vega, E. Gaillard, S. Narayanan, A. Sandy, Q. Zhang, E.M. Dufresne, G. Foffi, P. Grybos, P. Kmon, P. Maj, R. Szczygiel, Hard-sphere-like dynamics in highly concentrated alpha-crystallin suspensions, Physical Review E 97 (2018).

[48] P.S. Sarangapani, S.D. Hudson, K.B. Migler, J.A. Pathak, The Limitations of an Exclusively Colloidal View of Protein Solution Hydrodynamics and Rheology, Biophysical Journal 105 (2013) 2418-2426.

[49] I. Kohli, S. Alam, B. Patel, A. Mukhopadhyay, Interaction and diffusion of gold nanoparticles in bovine serum albumin solutions, Applied Physics Letters 102 (2013).

[50] S. Zorrilla, G. Rivas, A.U. Acuna, M.P. Lillo, Protein self-association in crowded protein solutions: A time-resolved fluorescence polarization study, Protein Science 13 (2004) 2960-2969.

[51] J.J.H. Wong, S.K. Wright, I. Ghozalli, R. Mehra, K. Furuya, D.S. Katayama, Simultaneous HighThroughput Conformational and Colloidal Stability Screening Using a Fluorescent Molecular Rotor Dye, 4-(4-(Dimethylamino)styryl)-N-Methylpyridinium lodide (DASPMI), Journal of Biomolecular Screening 21 (2016) 842-850.

[52] P.M. Tessier, H.R. Johnson, R. Pazhianur, B.W. Berger, J.L. Prentice, B.J. Bahnson, S.I. Sandler, A.M. Lenhoff, Predictive crystallization of ribonuclease $A$ via rapid screening of osmotic second virial coefficients, Proteins-Structure Function and Genetics 50 (2003) 303-311.

[53] M.R.G. Kopp, A. Villois, U.C. Palmiero, P. Arosio, Microfluidic diffusion analysis of the size distribution and micro-rheological properties of antibody solutions at high concentrations, Ind.Chem.Res. 57 (2018) 7112-7120. 
Legend to Figures

Figure 1: Relative viscosity $\left(\eta / \eta_{0}\right)$ of a range of sucrose concentrations (from $0.1-50 \%$ $(w / w))$ measured using a Vilastic-3 (squares), and inverse ratio of diffusion times, $\tau_{D} / \tau_{D, 0}$, determined by FCS using ATTO-Rho6G (circles) and IgG-AF (triangles). Plots represent mean \pm std. dev for $n=3$.

Figure 2: Normalised autocorrelation function (ACF) for IgG-AF (2 $\mu \mathrm{g} / \mathrm{mL})$ in buffer alone (pH 5) and in COE-03 solutions (5 to $125 \mathrm{~g} / \mathrm{L}, \mathrm{pH} 5)$. The average time the fluorescent probe spends in the focal volume is given by the characteristic decay time of the ACF (Equation (5)).

Figure 3: variation of the relative viscosity, $\eta / \eta_{0}$, measured using a RheoChip and of the ratio of diffusion times, $\tau_{D} / \tau_{D, 0}$, for tracers of increasing size: ATTO-Rho6G, TMR peptide, BSA-AF, IgG-AF and IgM-AF in crowded solutions of (a) BSA at pH 7, (b) COE-03 and (c) COE-19 (see key; all at $T=20^{\circ} \mathrm{C}$ ). The red line corresponds to the ratio of diffusion times based on hard sphere model.

Figure 4: correlation between k-values obtained with IgG-AF/FCS derived and RheoChip derived data (solid red line). The shaded area corresponds to 95\% confidence interval) and the dashed line represents the case for which GSE is valid and equal k-values for FCS and RheoChip.

Figure 5: variation of parameter $k$ (from model 1) as a function of the interaction parameter $k_{D}$ (left).Conditions mAbs in 20mM HisOAc pH 5.5, 30mM HisCl pH 6.0 and 200mM ArgHCl pH 5.0 are adapted from Conolly et al. [44] 


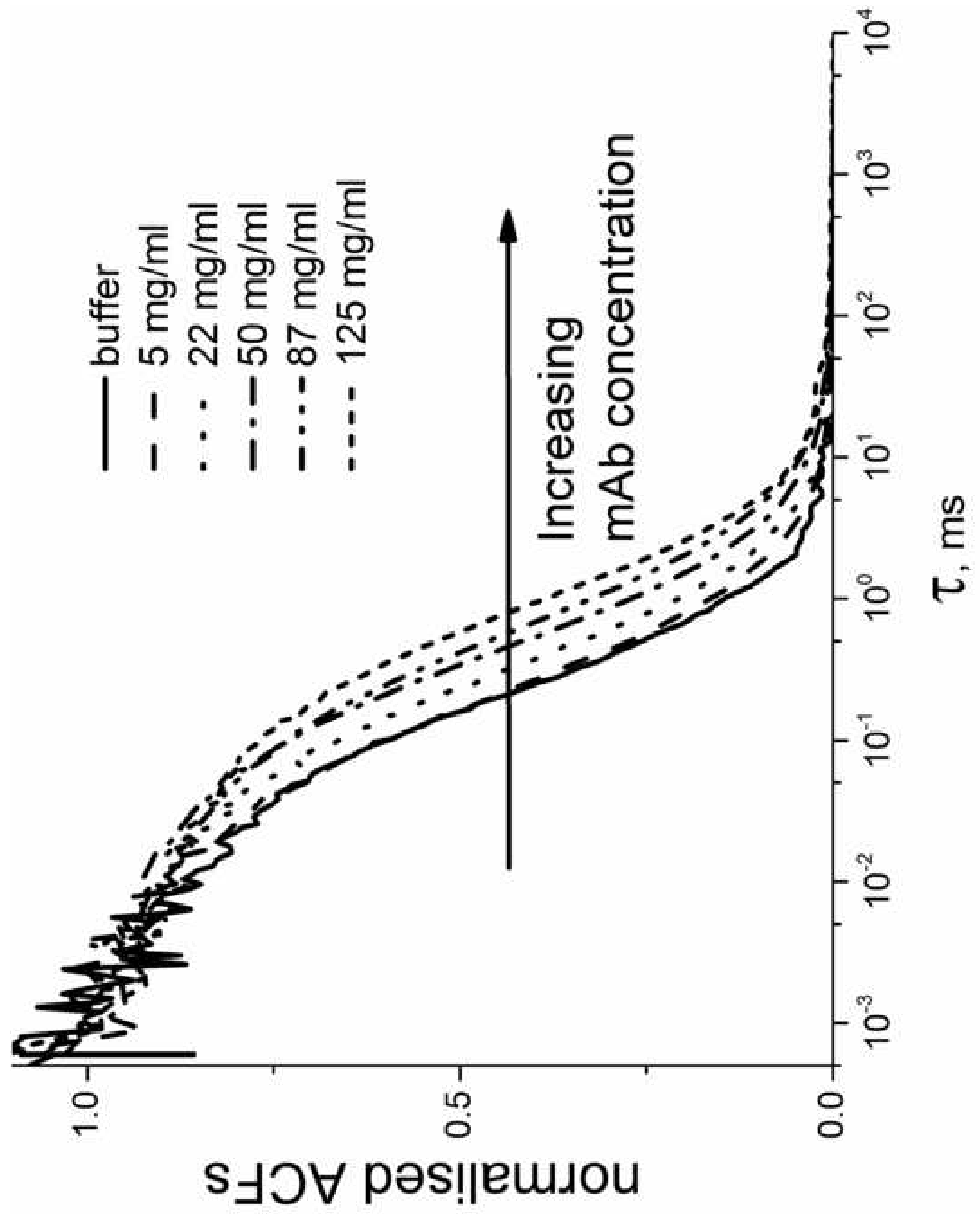


a.

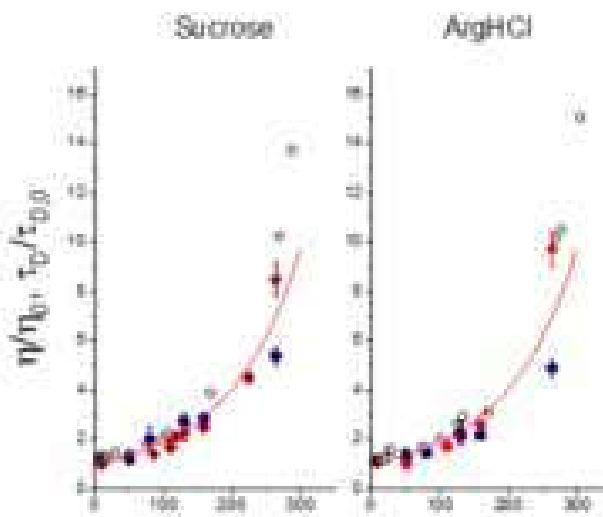

Avglu

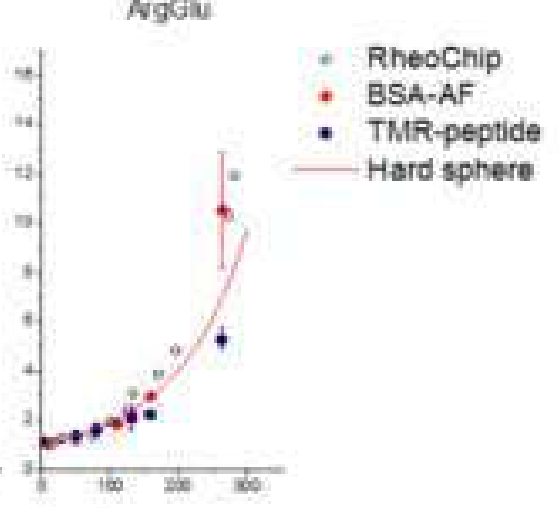

BSA concentration, $\mathrm{mg} / \mathrm{mL}$

b.

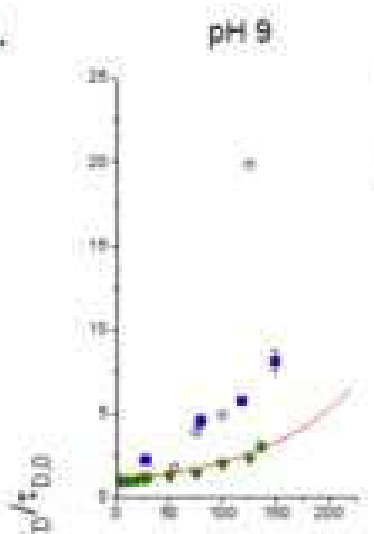

$\mathrm{pH} 6.5$

$\sum$
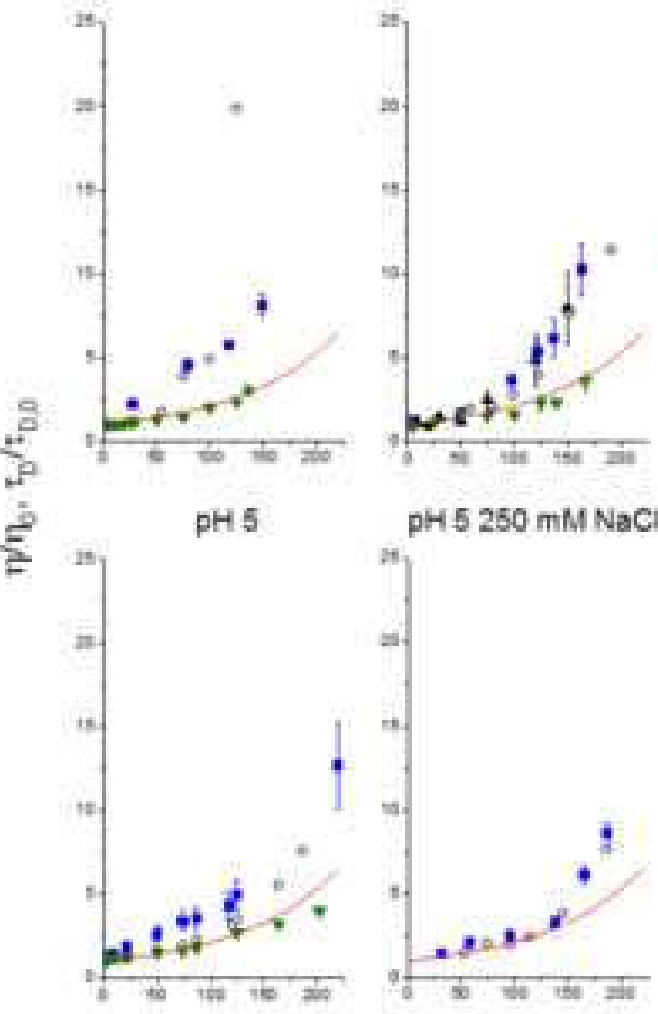

- RheoChip

* IgMAF

- iggaf

- ATTO-Rho6G

Hard sphere model

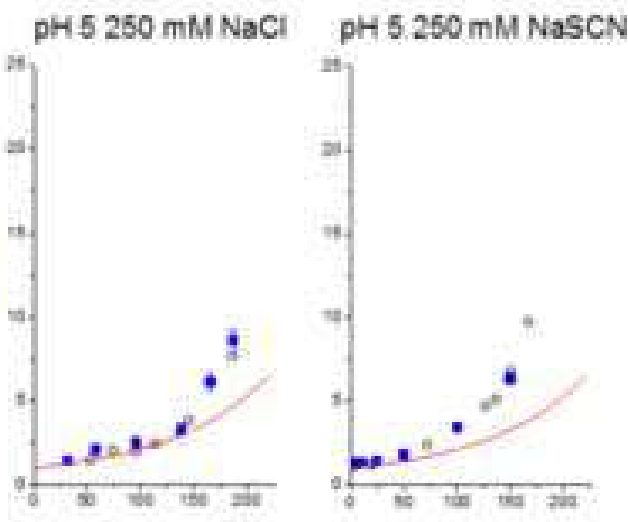

COE-03 concentration, $\mathrm{mg} / \mathrm{mL}$

c.

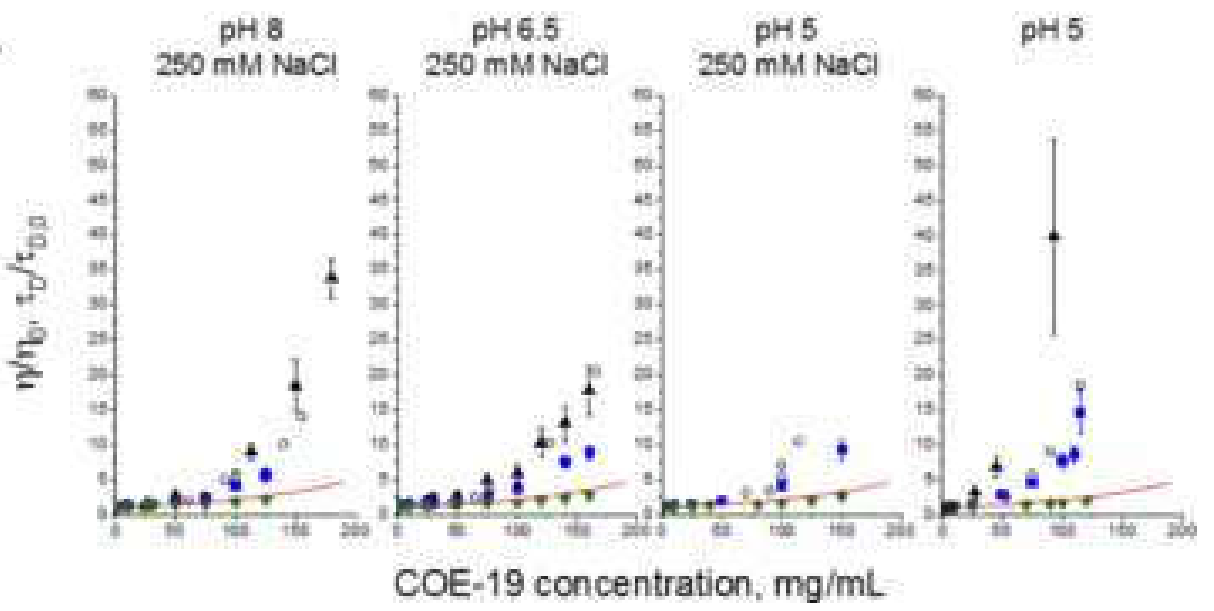




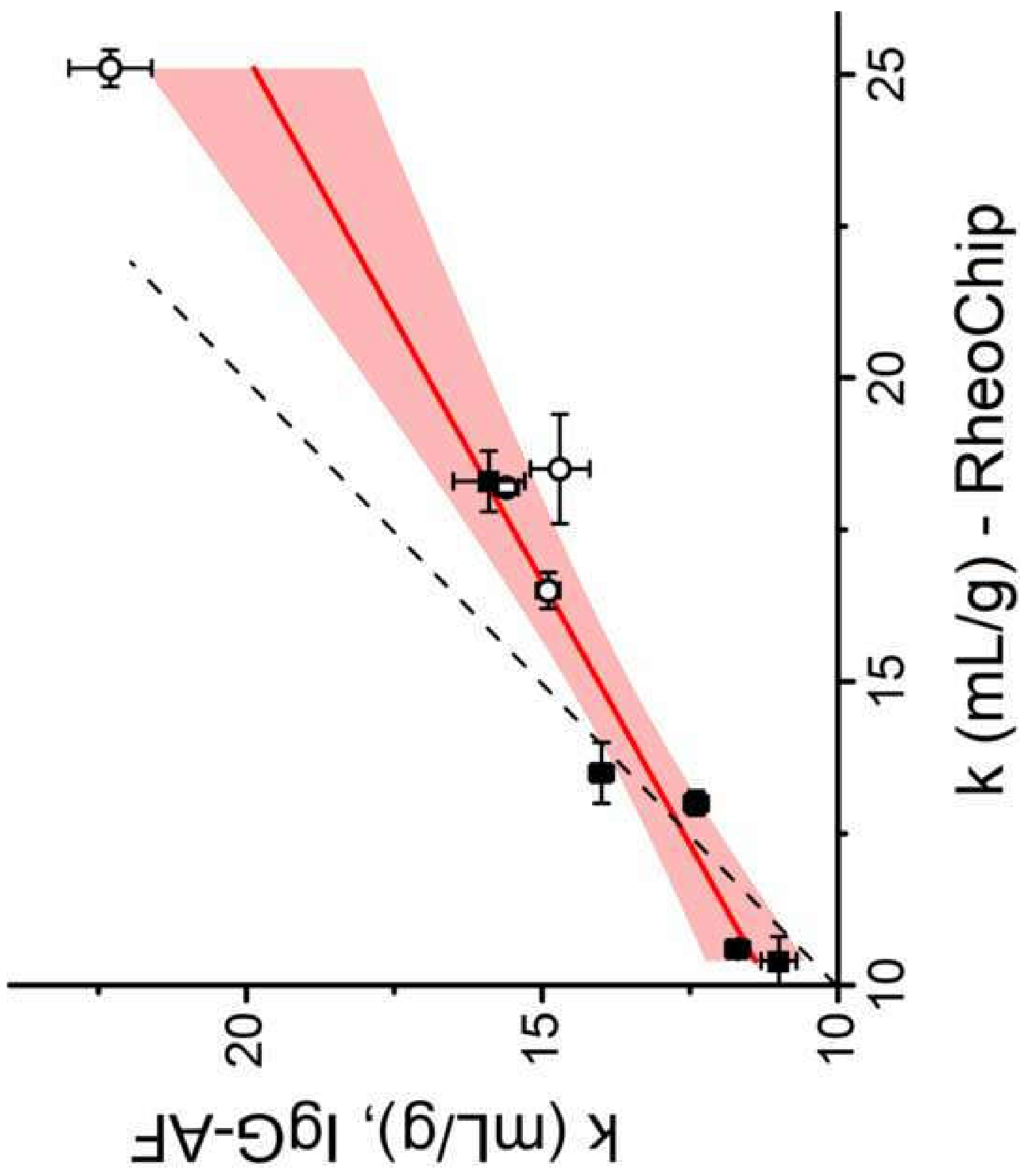

$\stackrel{0}{\overline{5}}$ 


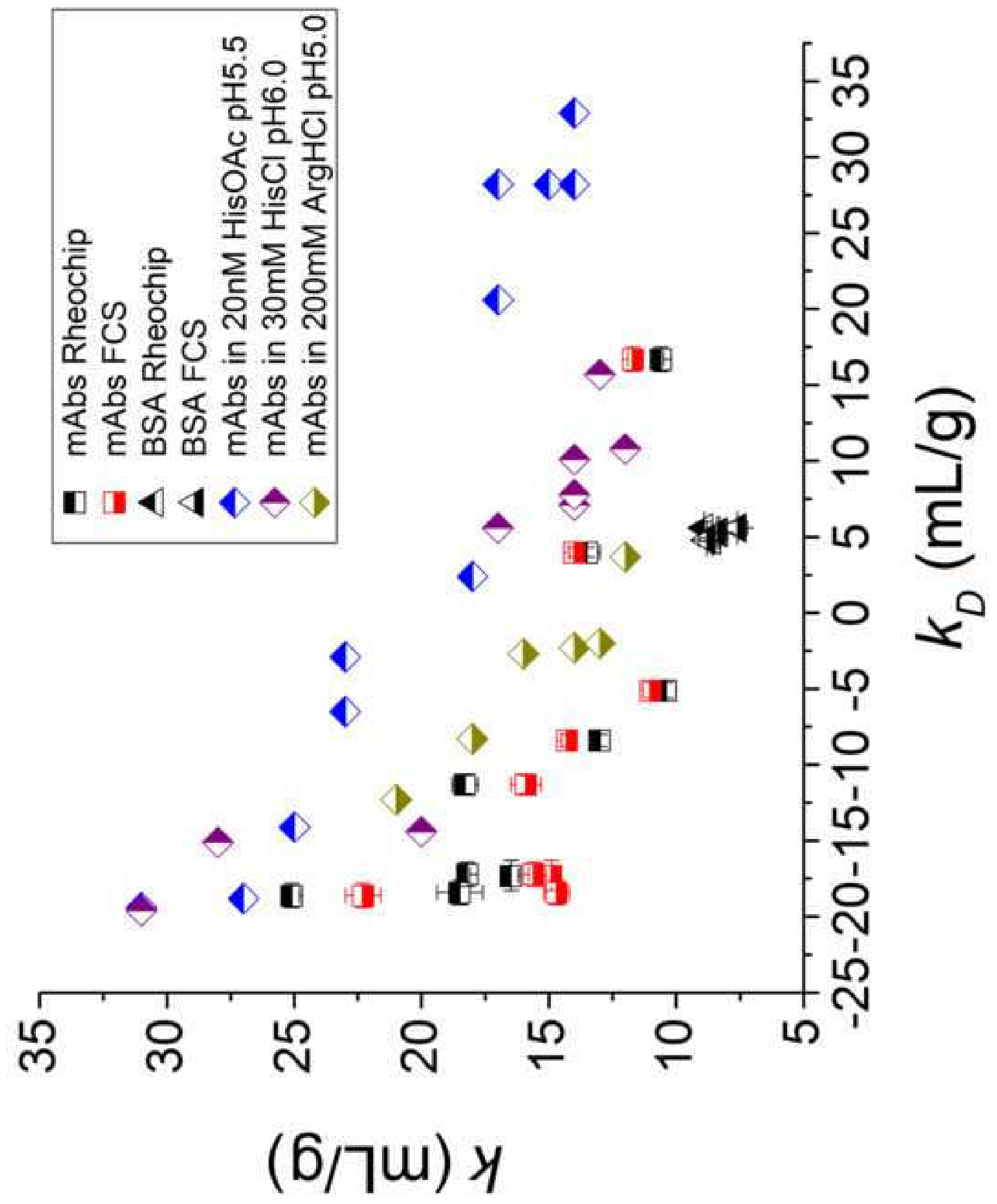


Click here to access/download

Table

Tables final version.docx 
Click here to access/download e-Component Supplementary information.docx 